\title{
Economic Burden of Chronic Hand Eczema: A Review
}

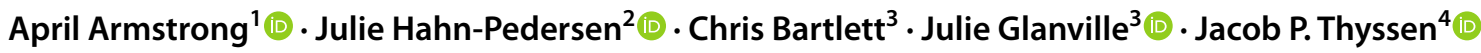

Accepted: 13 December 2021 / Published online: 8 March 2022

(c) The Author(s) 2022

\begin{abstract}
There has been no extensive synthesis of studies evaluating the cost of chronic hand eczema (CHE). This review evaluated the societal costs, healthcare resource utilisation, missed work time and job loss due to CHE. MEDLINE and 16 other databases and websites were searched in October 2020 for studies meeting prespecified inclusion criteria. Studies conducted in Europe, Australia, New Zealand or the Americas were included. Two reviewers independently assessed titles and abstracts, and full-text papers published in English between 2000 and 2020, for relevance. Data extraction was carried out by one reviewer and checked by a second reviewer. All data were based on costs between 2001 and 2013 but have been inflated to 2020 prices and converted to US dollars and Euros. A total of 30 studies (reported in 33 publications) were included in the synthesis. Mean total societal costs per year per patient ranged from $\$ 2549$ (€1813) to $\$ 10,883$ (€7738). Pharmacological therapy was, on average, $\$ 28.34$ (€20.15) per month in Italy and \$36.49 (€25.94) per month for emollients in Switzerland. Yearly treatment costs were $\$ 599.05$ ( $€ 425.92)$ for drugs, including topical corticosteroids, topical calcineurin inhibitors, other topical treatments and oral treatments, and $\$ 178.40$ for emollients, in Germany. CHE was associated with hospitalisation costs ranging from $\$ 81.86$ ( $€ 58.20$ ) per patient per month (US) to $\$ 105.04$ ( $€ 74.68$ ) per patient per month (Italy) and $\$ 639.59$ (€454.75) per year (Germany). Up to 57\% of patients took sick leave and up to $25 \%$ reported job loss/job change due to CHE. This review confirms the significant cost burden of CHE. Given the paucity of studies estimating the monetary costs of absenteeism, presenteeism and job loss associated with CHE, current mean societal costs are likely underestimated. Uncontrolled disease may also lead to increased costs to patients and society.
\end{abstract}

\section{Introduction}

Hand eczema (HE), or hand dermatitis, is an inflammatory skin condition that may be chronic in some patients, and its socioeconomic burden is considerable [1]. The severity of HE varies among patients and can lead to significant limitations in earning potential and absenteeism [2-4]. While HE may occur following excessive or prolonged exposure to irritants, allergens, or proteins, individuals with a history of atopic dermatitis (AD) are at increased risk for developing HE [5].

Chris Bartlett

Chris.bartlett@york.ac.uk

1 Department of Dermatology, Keck School of Medicine at University of Southern California, Los Angeles, CA, USA

2 Leo Pharma A/S, Ballerup, Denmark

3 York Health Economics Consortium Ltd, York YO10 5NQ, UK

4 Department of Dermatology Bispebjerg Hospital, University of Copenhagen, Copenhagen, Denmark

\section{Key Points}

The direct and indirect economic costs of chronic hand eczema (CHE) are comparable with other dermatological conditions.

Ongoing development of new therapies means the direct economic burden of CHE may be higher than estimated in this literature review, since some of the included studies are more than 10 years old.

There are few studies of the economic cost burden of absenteeism, presenteeism and job change in CHE.

The societal costs of CHE are likely underestimated. 
HE can range in severity from mild to severe, and the clinical course from acute to chronic [6]. The European Society of Contact Dermatitis Guideline Development Group defines chronic HE (CHE) as the persistence of HE for more than 3 months, or when the condition reoccurs at least twice within 12 months [6]. Management involves different interventions (avoidance, emollients, topical corticosteroids [TCS], phototherapy, oral immunosuppressants, oral retinoids [alitretinoin], gloves) to control the disease and treat the flare-ups [6].

Understanding costs is important to facilitate healthcare resource allocation decisions and to know the extent of cost burdens for patients and payers. CHE impacts patients' ability to function and/or work, therefore it is important to characterize its societal economic burden. The costs of HE have been previously reported by Politiek [1] in a systematic literature review of cost-of-illness studies, but that review did not focus on CHE. This review summarizes the current evidence on the costs of CHE with regard to its costs to society, in terms of economic costs (direct medical costs, direct non-medical costs and indirect costs), healthcare resource utilisation, missed work time and job losses (Table 1).

\section{Methods of the Review}

This review was conducted following Cochrane and Centre for Reviews and Dissemination (CRD) guidance [7, 8] and followed a protocol developed a priori (PROSPERO registration number: CRD42020215195). The protocol provides full details of the review methods employed.

\subsection{Eligibility Criteria}

Studies of patients of all ages with CHE were eligible for inclusion. Studies in which the definition of 'chronic' was not reported were eligible if the duration of CHE was reported to be longer than 3 months or where patients visited a dermatologist or a hospital. Outcomes of interest included societal costs in general (cost of illness), specific direct medical costs (healthcare related), direct non-medical costs (non-medical economic costs related to the condition) and indirect costs (morbidity, e.g. work productivity), and costs associated with healthcare resource utilisation (resource use, e.g. staff time).

Only studies published in English since 2000 and conducted in Europe, Australia, New Zealand or the Americas were included.

\subsection{Searches}

MEDLINE, the NHS Economic Evaluations Database (EED), the Cochrane Central Register of Controlled
Table 1 Components of the burden of chronic hand eczema

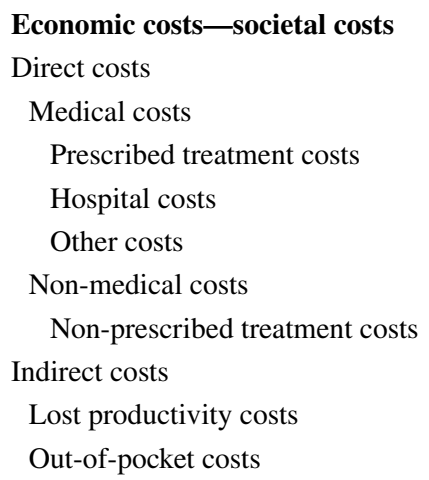

Non-economic healthcare resource utilisation costs

Hospitalisations

Consultations

Laboratory evaluation and treatments

Work impairment and missed work time

Absenteeism and presenteeism

Job change

Trials, the Health Technology Assessment (HTA) database, EMBASE, and a range of websites were searched in July 2018 and the searches were updated in October 2020 (Online Resource 1).

\subsection{Screening, Data Extraction and Quality Assessment}

Results of searches were downloaded in a tagged format and loaded into bibliographic software (EndNote) and deduplicated against one another. Results from resources that did not allow export in a format compatible with EndNote were saved in Microsoft Word or Excel (Microsoft Corporation, Redmond, WA, USA) documents as appropriate and manually deduplicated. A single researcher removed obviously irrelevant records. Two reviewers then independently assessed the remaining titles and abstracts for eligibility followed by an assessment of the full-text papers. Disagreements at each stage were resolved by discussion or the involvement of a third reviewer. One reviewer extracted data, and quality assessed studies (Online Resource 2). A second reviewer checked the data and the study quality. A narrative synthesis of evidence was performed to summarize the findings from the included primary studies.

\section{Results}

\subsection{Included Studies}

Thirty studies (33 papers) were eligible (Fig. 1). 


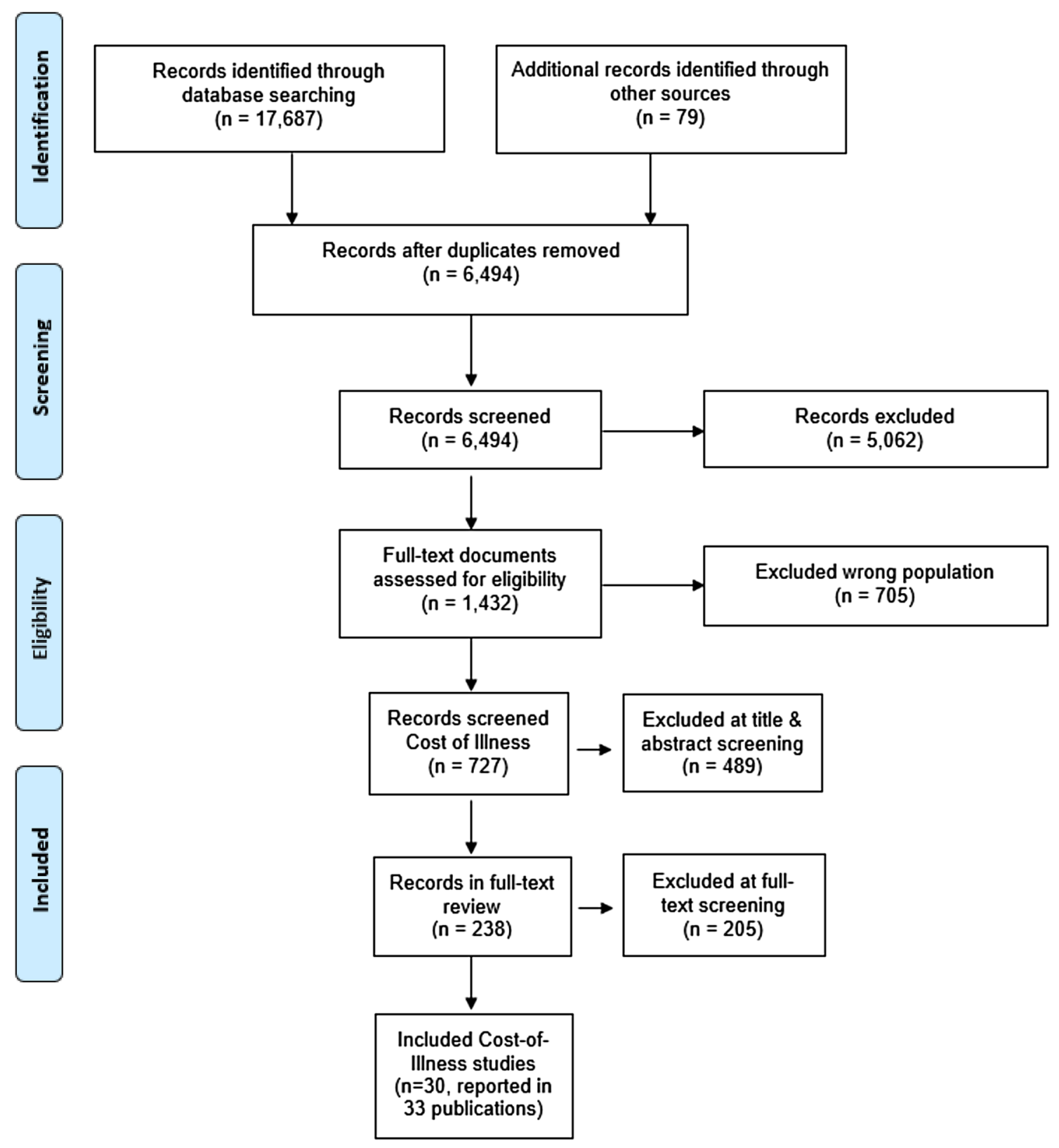

Fig. 1 PRISMA diagram of record selection process. PRISMA preferred reporting items for systematic reviews and meta-analyses

\subsection{Cost Studies}

Costs were converted to 2020 prices using country-specific price indices [9] and converted to US dollars and Euros using Purchasing Power Parities [10].

\subsubsection{Direct Costs}

Six studies reported direct costs [11-16] for five countries (Tables 2, 3 and 4). In the studies reporting costs of specific treatments, the least costly treatment was emollients $(\$ 14.87$ per patient per month [pppm] in Germany) and the costliest was alitretinoin (30 mg capsule, \$702.44 pppm in Switzerland). Costs were also reported for TCS, ciclosporin, psoralen plus ultraviolet $\mathrm{A}$ (PUVA) and azathioprine for various countries, as well as for supportive care and remission (details are reported in Table 2). Overall mean pppm costs were reported for pharmacological therapy in two studies (\$28.34 in Italy and \$165.02 in the US) and non-pharmacological therapy (e.g. emollients, galenic formulations and ultraviolet irradiation) [\$29.21 in Italy]. 
Table 2 Treatment costs

\begin{tabular}{|c|c|c|c|c|}
\hline References & Country & Cost & US\$ (2020) & $€(2020)$ \\
\hline Cortesi et al. [15] & Italy & $\begin{array}{l}\text { Mean per patient-month cost of pharmacological therapy (mini- } \\
\text { mum-maximum) } \\
\text { Mean per patient-month cost of non-pharmacological therapy, } \\
\text { e.g. emollients, galenic formulations, and ultraviolet irradiation } \\
\text { (minimum-maximum) }\end{array}$ & $\begin{array}{l}\$ 28.34 \\
(\$ 0-\$ 144.92) \\
\$ 29.21 \\
(\$ 0-\$ 161.71)\end{array}$ & $\begin{array}{l}€ 20.15 \\
(€ 0-€ 103.04) \\
€ 20.77 \\
(€ 0-€ 114.98)\end{array}$ \\
\hline \multirow[t]{2}{*}{ Fowler et al. [16] } & USA & Per patient monthly costs (mean \pm SE) & & \\
\hline & & $\begin{array}{l}\text { Prescription drugs } \\
\text { Outpatient services }\end{array}$ & $\begin{array}{l}\$ 165.02( \pm \$ 8.47) \\
\$ 255.71( \pm \$ 20.02)\end{array}$ & $\begin{array}{l}€ 117.33( \pm € 6.02) \\
€ 181.81( \pm € 14.23)\end{array}$ \\
\hline \multirow[t]{7}{*}{ NICE TA177 [12] } & UK & Acquisition cost (per cycle of therapy) & & \\
\hline & & $\begin{array}{l}\text { Alitretinoin } \\
\text { Ciclosporin } \\
\text { PUVA } \\
\text { Azathioprine }\end{array}$ & $\begin{array}{l}\$ 716.17 \\
\$ 307.16 \\
\$ 960.14 \\
\$ 31.34\end{array}$ & $\begin{array}{l}€ 509.20 \\
€ 218.39 \\
€ 682.66 \\
€ 22.28\end{array}$ \\
\hline & & $\begin{array}{l}\text { Refractory costs for alitretinoin, ciclosporin, PUVA, azathioprine } \\
\text { (per } 4 \text { weeks) }\end{array}$ & $\$ 20.60$ & $€ 14.65$ \\
\hline & & Supportive costs (per 4 weeks) & & \\
\hline & & $\begin{array}{l}\text { Alitretinoin } \\
\text { Ciclosporin } \\
\text { PUVA } \\
\text { Azathioprine }\end{array}$ & $\begin{array}{l}\$ 101.92 \\
\$ 99.88 \\
\$ 91.50 \\
\$ 95.22\end{array}$ & $\begin{array}{l}€ 72.47 \\
€ 71.01 \\
€ 65.06 \\
€ 67.70\end{array}$ \\
\hline & & Remission costs (4 weeks) & & \\
\hline & & $\begin{array}{l}\text { Alitretinoin } \\
\text { Ciclosporin } \\
\text { PUVA } \\
\text { Azathioprine }\end{array}$ & $\begin{array}{l}\$ 9.70 \\
\$ 20.60 \\
\$ 20.60 \\
\$ 20.60\end{array}$ & $\begin{array}{l}€ 6.90 \\
€ 14.65 \\
€ 14.65 \\
€ 14.65\end{array}$ \\
\hline \multirow[t]{4}{*}{ Blank et al. [11] } & Switzerland & Mean cost per month & & \\
\hline & & $\begin{array}{l}\text { Alitretinoin ( } 30 \mathrm{mg} \text { capsules) } \\
\text { Emollients }\end{array}$ & $\begin{array}{l}\$ 702.44 \\
\$ 36.49\end{array}$ & $\begin{array}{l}€ 499.43 \\
€ 25.94\end{array}$ \\
\hline & & Average cost per month & & \\
\hline & & $\begin{array}{l}\text { Patients taking alitretinoin }(30 \mathrm{mg}) \\
\text { Patients taking placebo } \\
\text { Patients clear or almost clear maintenance } \\
\text { Severe non-responders }\end{array}$ & $\begin{array}{l}\$ 797.72 \\
\$ 75.01 \\
\$ 46.63 \\
\$ 191.57\end{array}$ & $\begin{array}{l}€ 567.18 \\
€ 53.33 \\
€ 33.15 \\
€ 136.21\end{array}$ \\
\hline \multirow[t]{2}{*}{ Augustin et al. [14] } & Germany & Yearly treatment costs & & \\
\hline & & $\begin{array}{l}\text { Topical corticosteroids } \\
\text { Emollients }\end{array}$ & $\begin{array}{l}\$ 599.05 \\
\$ 178.40\end{array}$ & $\begin{array}{l}€ 425.92 \\
€ 126.84\end{array}$ \\
\hline
\end{tabular}

PUVA psoralen-ultraviolet A therapy, SE standard error

Table 3 Hospital costs

\begin{tabular}{|c|c|c|c|c|}
\hline References & Country & Cost & US\$ (2020) & $€(2020)$ \\
\hline Cortesi et al. [15] & Italy & $\begin{array}{l}\text { Mean per patient-month cost of hospitalisation (mini- } \\
\text { mum-maximum) }\end{array}$ & $\$ 105.04(\$ 0-\$ 1425.97)$ & $€ 74.68(€ 0-€ 1013.86)$ \\
\hline Fowler et al. [16] & US & Mean per patient-month cost of inpatient services $( \pm$ SE) & $\$ 81.86( \pm \$ 12.18)$ & $€ 58.20( \pm € 8.66)$ \\
\hline Augustin et al. [14] & Germany & Yearly inpatient cost & $\$ 639.59$ & $€ 454.75$ \\
\hline
\end{tabular}

Three studies reporting hospital costs [14-16] varied in terms of the costs included and how they were estimated. Mean hospitalisation pppm costs ranged from \$53.30 in Germany to $\$ 105.04$ in Italy (Table 3). Four studies reported on other types of costs associated with CHE [11, 13-15], which included costs for tests and pregnancy testing as well as oral contraceptives (Table 4). 
Table 4 Other direct costs

\begin{tabular}{|c|c|c|c|c|}
\hline References & Country & Cost & US\$ (2020) & $€(2020)$ \\
\hline \multirow[t]{4}{*}{ Cortesi et al. [15] } & \multirow[t]{4}{*}{ Italy } & Mean (minimum-maximum) per patient-month cost & & \\
\hline & & Medical consultation & $\begin{array}{l}\$ 63.96 \\
(\$ 0-\$ 627.03)\end{array}$ & $\begin{array}{l}€ 45.48 \\
(€ 0-€ 445.82)\end{array}$ \\
\hline & & Diagnostic examinations & $\begin{array}{l}\$ 30.51 \\
(\$ 0-\$ 240.03)\end{array}$ & $\begin{array}{l}€ 21.69 \\
(€ 0-€ 170.66)\end{array}$ \\
\hline & & $\begin{array}{l}\text { Other products (or instruments, such as gloves or gauze bandages, } \\
\text { vacuum cleaners, and cosmetic) }\end{array}$ & $\begin{array}{l}\$ 42.37 \\
(\$ 0-\$ 1460.22)\end{array}$ & $\begin{array}{l}€ 30.13 \\
(€ 0-€ 1038.22)\end{array}$ \\
\hline \multirow[t]{8}{*}{ Blank et al. [11] } & \multirow[t]{8}{*}{ Switzerland } & Mean cost per month & & \\
\hline & & Pregnancy testing + oral contraceptives & $\$ 27.37$ & $€ 19.46$ \\
\hline & & Dermatologist visits & $\$ 39.53$ & $€ 28.11$ \\
\hline & & Lipid monitoring tests & $\$ 16.22$ & $€ 11.53$ \\
\hline & & PUVA/311 nm (topical/oral) & $\$ 174.34$ & $€ 123.96$ \\
\hline & & $\begin{array}{l}\text { Topical corticosteroids total (assumption was that } 25 \% \text { of patients were } \\
\text { treated with Class I-III and } 75 \% \text { were treated with Class IV topical } \\
\text { corticosteroids) }\end{array}$ & $\$ 29.40$ & $€ 20.90$ \\
\hline & & Topical corticosteroids Class I-III & $\$ 42.57$ & $€ 30.27$ \\
\hline & & Topical corticosteroids Class IV & $\$ 25.34$ & $€ 18.02$ \\
\hline \multirow[t]{12}{*}{ van Gils et al. [13] } & \multirow[t]{12}{*}{ The Netherlands } & Cost per consultation & & \\
\hline & & Dermatologist & $\$ 117.80$ & $€ 83.76$ \\
\hline & & General practitioner & $\$ 45.82$ & $€ 32.58$ \\
\hline & & Clinical occupational physician & $\$ 37.21$ & $€ 26.46$ \\
\hline & & Specialized nurse & $\$ 97.44$ & $€ 69.28$ \\
\hline & & Occupational physician & $\$ 37.21$ & $€ 26.46$ \\
\hline & & Homeopath & $\$ 99.01$ & $€ 70.40$ \\
\hline & & Internist & $\$ 117.80$ & $€ 83.76$ \\
\hline & & Psychologist & $\$ 137.49$ & $€ 97.76$ \\
\hline & & Light therapy & $\$ 77.03$ & $€ 54.77$ \\
\hline & & Insurance physician & $\$ 70.45$ & $€ 50.09$ \\
\hline & & Acupuncture & $\$ 73.34$ & $€ 52.14$ \\
\hline \multirow[t]{4}{*}{ Augustin et al. [14] } & \multirow[t]{4}{*}{ Germany } & Yearly costs & & \\
\hline & & Outpatient care & $\$ 172.32$ & $€ 122.52$ \\
\hline & & Diagnostics & $\$ 397.34$ & $€ 282.51$ \\
\hline & & UV therapy & $\$ 457.14$ & $€ 325.03$ \\
\hline
\end{tabular}

PUVA psoralen-ultraviolet A therapy, $U V$ ultraviolet

\subsubsection{Indirect Costs}

Indirect costs (two studies $[14,15])$ reported lost productivity or out-of-pocket costs. Lost productivity costs for CHE ranged from $\$ 623.77$ per year in Germany $(n=223$; CHE refractory to potent TCS) [14] to $\$ 285.30 \mathrm{pppm}$ in Italy ( $n=104$; severe CHE) [15]. Out-of-pocket costs for CHE were reported in two studies (\$335.98 per year in Germany [14] and $\$ 63.40$ pppm in Italy [15]).

\subsubsection{Total Costs}

Five studies [13-17] (four countries) reported the total societal cost of CHE (total direct plus indirect costs). The total costs per year per patient with CHE ranged between $\$ 2549$ and $\$ 10,883$, based on studies in the US and Europe. The highest estimate was in patients with occupation-related CHE. See Table 5 for the total costs reported by each study. These studies are difficult to synthesise because of differences in national health care systems and patient management protocols.

\subsection{Studies Reporting Resource Use}

Fifteen studies reported resource use data $[4,11,14,15,19$, $21-25,28-32]$. 
Table 5 Cost of illness of chronic hand eczema

\begin{tabular}{|c|c|c|c|c|}
\hline References & Country & Cost & US\$ (2020) & $€(2020)$ \\
\hline Cortesi et al. [15] & Italy & $\begin{array}{l}\text { Mean total costs per patient-month (mini- } \\
\text { mum-maximum) }\end{array}$ & $\begin{array}{l}\$ 652.66 \\
(\$ 53.51-\$ 3595.59)\end{array}$ & $\begin{array}{l}€ 464.04 \\
(€ 38.05-€ 2556.46)\end{array}$ \\
\hline Fowler et al. [16] & USA & Total direct medical cost per month & $\begin{array}{l}\$ 452.05 \\
(\mathrm{SE} \$ 32.35)\end{array}$ & $\begin{array}{l}€ 321.41 \\
(\mathrm{SE} € 23.00)\end{array}$ \\
\hline \multirow[t]{15}{*}{ Diepgen et al. [17] } & \multirow[t]{15}{*}{ Germany } & Total yearly costs & & \\
\hline & & SHI patients & $\$ 3440.26$ & $€ 2446.02$ \\
\hline & & Direct medical costs & $\$ 2816.48$ & $€ 2002.52$ \\
\hline & & Indirect costs & $\$ 623.77$ & $€ 443.50$ \\
\hline & & OHI patients & $\$ 10,883.20$ & $€ 7737.96$ \\
\hline & & Direct medical costs & $\$ 5349.57$ & $€ 3803.54$ \\
\hline & & Indirect costs & $\$ 5532.17$ & $€ 3933.37$ \\
\hline & & Non-working SHI patients & $\$ 2007.18$ & $€ 1427.10$ \\
\hline & & Work-unaffected SHI patients & $\$ 2316.87$ & $€ 1647.29$ \\
\hline & & Work-impaired SHI patients & $\$ 8142.67$ & $€ 5789.44$ \\
\hline & & Direct costs & $\$ 5115.84$ & $€ 3637.36$ \\
\hline & & Indirect costs & $\$ 3026.83$ & $€ 2152.08$ \\
\hline & & Work disease $\mathrm{OHI}$ patients & $\$ 12,500.33$ & $€ 8887.73$ \\
\hline & & Direct costs & $\$ 5349.57$ & $€ 3803.54$ \\
\hline & & Indirect costs & $\$ 5532.17$ & $€ 3933.37$ \\
\hline \multirow[t]{3}{*}{ Augustin [14] } & \multirow[t]{3}{*}{ Germany } & Total yearly societal cost per patient & $\$ 3440.26$ & $€ 2446.02$ \\
\hline & & Direct costs & $\$ 2816.48$ & $€ 2002.52$ \\
\hline & & Indirect costs & $\$ 623.77$ & $€ 443.50$ \\
\hline \multirow[t]{7}{*}{ van Gils [13] } & \multirow[t]{7}{*}{ The Netherlands } & Mean (SD) cost per year per patient & & \\
\hline & & Integrated care- total societal costs & $\$ 5838.46(1290.34)$ & $€ 4151.15$ (917.43) \\
\hline & & Direct costs & $\$ 1546.79(129.74)$ & $€ 1099.77(92.25)$ \\
\hline & & Indirect costs & $\$ 4291.67$ (1247.77) & $€ 3051.38$ (887.16) \\
\hline & & Usual care-total societal costs & $\$ 2549.26(694.33)$ & $€ 1812.52(493.67)$ \\
\hline & & Direct costs & $\$ 775.42(76.02)$ & $€ 551.32(54.05)$ \\
\hline & & Indirect costs & $\$ 1773.84(659.87)$ & $€ 1261.20(469.17)$ \\
\hline
\end{tabular}

$O H I$ occupational health insurance, $S D$ standard deviation, $S E$ standard error, $S H I$ statutory health insurance

\subsubsection{Hospitalisations}

Three studies reported hospitalisations [14, 15, 25]. In Italy $(n=104)$, patients spent a mean of 0.2 days $(0.0-5.4)$ in hospital per month and a mean of 0.03 days $(0.0-2.1)$ attending hospital per month [15]. In Germany, 32\% (this was how the study described this datum, no further context was provided) of 1148 CHE patients received care as an inpatient [25] and inpatients $(n=223)$ spent 10.6 days (only data provided) in hospital per stay [14].

\subsubsection{Consultations}

Fourteen studies reported consultations for CHE $[4,11,14$, $15,19,21-24,28-32]$ (Table 6). Data on primary care visits were reported in different ways. A Finnish study $(n=1238$ across multiple trials) showed that primary care visit frequency depended on CHE subdiagnosis; approximately 33\% visited a doctor more than five times due to their CHE in the past 12 months [24]. Dermatologist/specialist consultations ranged from 0.9 visits per month in Italy to 3.1 visits over a 4-week period in Germany.

\subsubsection{Laboratory Evaluation and Treatments}

Four studies reported laboratory evaluations and treatments for CHE [11, 14, 15, 23] (Table 7). Resource use data were reported for diagnostic tests, which ranged from 0.6 per month in Italy in severe CHE to 1.7 per 4 weeks in Germany in CHE. Emollient resource use ranged from 1.2 products per month in Italy in severe CHE to 1.3 products per 4 weeks in Germany in CHE. Use of TCS was reported to be 1.1 products per 4 weeks in Germany in CHE. Ultraviolet sessions ranged from 4 per month in Italy in severe CHE to 8.6 per 4 weeks in Germany in CHE. An Italian study reported the use of 1.1 galenic products (not defined) per month 
Table 6 Consultations for chronic hand eczema

\begin{tabular}{|c|c|c|}
\hline References & Country & Consultations \\
\hline Thyssen et al. [24] & Finland & $\begin{array}{l}\text { > } 5 \text { visits (1982-83) } \\
\text { Hand eczema: } 34.5 \% \\
\text { Allergic contact dermatitis: } 34.9 \% \\
\text { Irritant dermatitis: } 11.9 \%\end{array}$ \\
\hline Cortesi et al. [15] & Italy & $\begin{array}{l}\text { Mean (minimum-maximum) number of specialist consultations (dermatologist, allergist, occupational } \\
\text { physician, immunologist, police doctor) per patient-month: } 0.9(0.0-2.7)\end{array}$ \\
\hline Augustin et al. [14] & Germany & Outpatient care visits in the last 4 weeks: 3.1 \\
\hline Apfelbacher et al. [32] & Germany & $\begin{array}{l}\text { After inclusion in the CARPE registry, trend of visits in the past } 12 \text { months } \\
\text { To the dermatologist: decreased strongly } \\
\text { To the general practitioner: decreased strongly }\end{array}$ \\
\hline Blank et al. [11] & Switzerland & Dermatologist visits per month: 1 \\
\hline Malkonen et al. [30] & Finland & Consulted a doctor within the last 7 years: $48 \%$ \\
\hline Herschel et al. [19] & Germany & $\begin{array}{l}\text { Mean number of physician visits in the past } 12 \text { months: } 4.0 \text { (SD 5.0) } \\
\text { No GP visits in past } 12 \text { months: } 22 \% \\
\text { GP care: } 21.4 \% \\
\text { Dermatologist care: } 74.9 \%\end{array}$ \\
\hline Josefson et al. [28] & Sweden & GP visit: $50 \%(n=129)$ \\
\hline Dibenedetti et al. [21] & USA & $\begin{array}{l}\text { Time frame in which patients sought medical attention after noticing symptoms of CHE }(n=163) \\
\text { Within } 6 \text { months: } 26 \% \\
6 \text { months to } 1 \text { year: } 34 \% \\
\text { Type of physician consulted for the first time } \\
\text { Primary care physician: } 54 \% \\
\text { Dermatologist: } 39 \%\end{array}$ \\
\hline Meding et al. [4] & Sweden & Visited a doctor $(n=868): 33 \%$ \\
\hline Hald et al. [22] & Denmark & $\begin{array}{l}\text { Self-reported duration of hand eczema symptoms within the past } 12 \text { months in relation to medical con- } \\
\text { sultations }(n=427) \\
\text { Not seen by a medical doctor ( } n=138 \text {, missing data } n=1) \\
\text { All the time: } 3.6 \% \\
\text { More than half the time: } 8.0 \% \\
\text { Half the time: } 5.8 \% \\
\text { Less than half the time: } 63.0 \% \\
\text { No symptoms: } 19.6 \% \\
\text { Seen by a GP but not a dermatologist }(n=102) \\
\text { All the time: } 9.8 \% \\
\text { More than half the time: } 12.7 \% \\
\text { Half the time: } 9.8 \% \\
\text { Less than half the time: } 45.1 \% \\
\text { No symptoms: } 22.5 \% \\
\text { Seen by a GP and a dermatologist }(n=184, \text { missing data } n=2) \\
\text { All the time: } 16.8 \% \\
\text { More than half the time: } 11.4 \% \\
\text { Half the time: } 14.7 \% \\
\text { Less than half the time: } 42.9 \% \\
\text { No symptoms: } 14.1 \%\end{array}$ \\
\hline Lerbaek et al. [29] & Denmark & $\begin{array}{l}(n=188) \\
1 \text { GP visit: } 25.3 \% \\
\text { 2-5 visits: } 22.6 \% \\
\text { > } 5 \text { visits: } 15.6 \% \\
\text { Total visits }(n=186): 63.4 \% \\
\text { Multivariate model to predict }>1 \text { medical consultation } \\
\text { Significant predictors, AD vs. no AD: OR } 3.0 \text { (95\% CI } 1.4-6.4), p=0.006\end{array}$ \\
\hline Petersen et al. [23] & Denmark & $\begin{array}{l}\text { Patients who have experienced periods of hand eczema since } 2007(n=419) \\
\text { GP visit: } 47 \% \\
\text { Dermatologist visit: } 40 \% \\
\text { 1 GP visit: } 23 \% \\
\text { > } 5 \text { GP visits: } 6 \% \\
1 \text { dermatologist visit: } 14 \% \\
\text { > } 5 \text { dermatologist visits: } 13 \%\end{array}$ \\
\hline
\end{tabular}


Table 6 (continued)

\begin{tabular}{lll}
\hline References & Country & Consultations \\
\hline Steengaard et al. [31] & Denmark & $(n=144)$ \\
& & Visits to dermatologist, total: $35.4 \%$ \\
& Intervention: $44.0 \%$ \\
& Control: $26.1 \%, p=0.20$ \\
\hline
\end{tabular}

$A D$ atopic dermatitis, $C H E$ chronic hand eczema, $C I$ confidence interval, $G P$ general practitioner, $O R$ odds ratio, $S D$ standard deviation

Table 7 Laboratory evaluations and treatments

\begin{tabular}{|c|c|c|}
\hline References & Country & Tests and treatments \\
\hline Blank et al. [11] & Switzerland & $\begin{array}{l}\text { Cost items, per month (used in a cost-effectiveness model) } \\
\text { Alitretinoin } 30 \mathrm{mg} \text { capsules: } 28 \times 30 \mathrm{mg} \text { (one capsule per day) } \\
\text { Emollients: } 200 \mathrm{~g} \\
\text { Pregnancy testing }+ \text { oral contraceptives: } 1 \text { test, } 21 \text { tablets } \\
\text { Lipid monitoring tests: } 1 \text { test } \\
\text { PUVA/ } 311 \mathrm{~nm} \text { (topical/oral): } 20 \text { cycles per } 10 \text { weeks in a } 6 \text {-month period ( } 3.33 \text { cycles per month) } \\
\text { Topical corticosteroids: } 60 \mathrm{~g}\end{array}$ \\
\hline Augustin et al. [14] & Germany & $\begin{array}{l}\text { Diagnostics tests in the last } 4 \text { weeks: } 1.7 \\
\text { Emollient products in the last } 4 \text { weeks: } 1.3 \\
\text { Topical corticosteroid products in the last } 4 \text { weeks: } 1.1 \\
\text { UV therapy (including PUVA) sessions in the last } 4 \text { weeks: } 8.6\end{array}$ \\
\hline Cortesi et al. [15] & Italy & $\begin{array}{l}\text { Mean (minimum-maximum) tests and treatments per patient-month } \\
\text { Number of diagnostic tests (patch test, prick test, RAST, PRIST, atopy patch test, skin biopsy, test } \\
\text { for hives, and immunofluorescence): } 0.6(0.0-2.1) \\
\text { Number of UV: } 4.0(4.0-4.0) \\
\text { Number of emollients: } 1.2(0.5-5.4) \\
\text { Number of galenic products: } 1.1(0.5-2.1) \\
\text { Number of other therapies (e.g. detergents/soaps, antiseptics): } 0.8(0.5-2.1)\end{array}$ \\
\hline Petersen et al. [23] & Denmark & $\begin{array}{l}\text { Emollient use: } 59 \% \text { of patients } \\
\text { Topical corticosteroid use: } 64 \% \text { of patients } \\
\text { Systemic therapy: } 7 \% \text { of patients } \\
\text { Phototherapy: } 6 \% \text { of patients }\end{array}$ \\
\hline
\end{tabular}

PRIST paper radioimmunosorbent test, PUVA psoralen-ultraviolet A therapy, RAST radioallergosorbent test, $U V$ ultraviolet

and 0.8 other therapies (detergents, soaps and antiseptics) per month in severe CHE. A definition of disease severity was not provided for these studies. One trial of alitretinoin in Germany $(n=223)$ reported that in a 4-week period, patients receiving routine care had a mean of 1.7 diagnostic tests (39\% of patients), 1.3 emollient products (91\%), 1.1 TCS products (84\%) and 8.6 phototherapy sessions (27\%) [14].

A hypothetical cost-effectiveness model of alitretinoin in Swiss CHE patients estimated the monthly number of tests and treatments [11]. The cost items included alitretinoin $30 \mathrm{mg}$ (one capsule daily), emollients ( $200 \mathrm{~g}$ ), pregnancy testing plus oral contraceptives (one test, 21 tablets), lipid monitoring tests (one test), topical/oral PUVA therapy/311 nm (3.33 cycles per month), and TCS (60 g).

\subsubsection{Absenteeism and Presenteeism}

Nineteen studies (20 publications) reported the proportion of patients taking sick leave (absenteeism) due to CHE ranged from 1 to $57 \%$ [4, 14, 16, 21-27, 29-32, 37-41]. The study period duration, disease severity, and sample sizes varied and these data are therefore difficult to interpret and compare (Table 8).

The study reporting sick leave due to CHE in $57 \%$ of patients $(n=579)$ was among patients with occupational HE [27]. There were no major differences between sick leave and different diagnoses of occupational $\mathrm{HE}$, although those with combined diagnoses of occupational contact dermatitis (e.g. irritant and allergic) had a high proportion of prolonged sick leave (more than 5 weeks per year). Prolonged sick leave was reported in $19 \%$ of patients, with a higher proportion in food-related occupations $(27.2 \%)$ compared 
Table 8 Work impairment and missed work time

\begin{tabular}{|c|c|c|}
\hline References & Country & Work impairment and missed work time \\
\hline Agner et al. [18] & Europe & $\begin{array}{l}\text { People with hand eczema and subdiagnoses of atopic eczema and allergic contact derma- } \\
\text { titis were associated with increased frequency of sick leave: } 0.122(p=0.023) \text { and } 0.128 \\
(p=0.032) \text {, respectively }\end{array}$ \\
\hline Apfelbacher et al. [25] & Germany & $\begin{array}{l}\text { Currently unable to work: } 21.6 \% \\
\text { Sick leave in the past } 12 \text { months (all patients): } 32.7 \%\end{array}$ \\
\hline Apfelbacher et al. [38] & Germany & $\begin{array}{l}\text { Sick leave in past } 12 \text { months } \\
>0-2 \text { weeks: } 48.6 \% \\
>2-6 \text { weeks: } 30.5 \% \\
>6 \text { weeks: } 20.9 \%\end{array}$ \\
\hline Apfelbacher et al. [32] & Germany & $\begin{array}{l}\text { Changed or given up their job because of CHE: } 5.4 \% \\
\text { Sick leave (in the past } 12 \text { months): } 35.3 \% \\
\text { Currently unable to work (at baseline): } 24.5 \%\end{array}$ \\
\hline Augustin et al. [14] & Germany & $\begin{array}{l}\text { Sick leave in the last year: } 33 \% \\
\text { Average number of days sick leave per year: } 7.2 \text { days }\end{array}$ \\
\hline Cazzanniga et al. [20] & Germany and Switzerland & $\begin{array}{l}\text { CHE in workers in food-handling jobs was strongly associated with the ability to work and } \\
\text { sick leave } \\
\text { In men, there was a strong association with long duration of hand eczema (> } 6 \text { years) and } \\
\text { job loss or change }\end{array}$ \\
\hline Diepgen et al. [17] & Germany & $\begin{array}{l}\text { Patients in employment who had sick leave in the last } 12 \text { months: } 42 \% \\
\text { Mean number of days of sick leave: } 35 \text { days }\end{array}$ \\
\hline Diepgen et al. [39] & Germany & $\begin{array}{l}\text { Sick leave due to hand eczema: } 28.4 \% \\
\text { Sick leave for more than } 5 \text { consecutive weeks: } 12.3 \%\end{array}$ \\
\hline Herschel et al. [19] & Germany & $\begin{array}{l}\text { Unable to work: } 24.7 \% \\
\text { Changed jobs due to disease: } 12.6 \%\end{array}$ \\
\hline Thyssen et al. [24] & Finland & $\begin{array}{l}\text { At least } 7 \text { days off sick: } 6 \% \\
\text { Change in job due to hand eczema: } 3 \% \\
\text { Receiving sickness pension because of the illness: } 2 \%\end{array}$ \\
\hline Malkonen et al. [30] & Finland & $\begin{array}{l}\text { Sick leave in the past } 7 \text { years because of hand eczema: } 23 \% \\
\text { Sick leave was associated with age ( } 45 \text { years or older) at the time of diagnosis, but not with } \\
\text { sex, diagnosis, atopy, occupation or specific work-related allergies } \\
\text { Job loss (unemployment and retirement) due to occupational hand eczema: } 25 \% \text { of patients } \\
\text { (most frequent among patients aged } 45 \text { years or older, in patients with allergic contact } \\
\text { dermatitis, or in food-related occupations) }\end{array}$ \\
\hline Fowler et al. [16] & USA & $\begin{array}{l}\text { Mean percentage of work time missed: } 4.08 \%(\mathrm{SE} \pm 11.03) \\
\text { Mean percentage of impairment while working: } 26.86 \%(\mathrm{SE} \pm 31.39) \\
\text { Percentage of overall work impairment: } 29.33 \%(\mathrm{SE} \pm 31.73)\end{array}$ \\
\hline Dibenedetti et al. [21] & USA & $\begin{array}{l}\text { Missed work or school activities over the previous } 3 \text { months: } 24 \% \\
\text { In patients who missed work or school over the previous } 3 \text { months: mean days missed: } 4.4 \\
\text { (SD 3.3) } \\
\text { Changed jobs or left job due to CHE: } 4 \% \\
\text { Short-term disability due to CHE: } 6 \% \text { ( } 3 \% \text { had applied for workers' compensation) }\end{array}$ \\
\hline Josefson et al. [28] & Sweden & Changed job due to hand eczema: $15.5 \%$ of women with hand eczema \\
\hline Meding et al. [4] & Sweden & $\begin{array}{l}\text { Median total sick leave time: } 38 \text { weeks (range 1-312) } \\
\text { At least } 7 \text { days (since 1983): } 6 \%\end{array}$ \\
\hline Agner [33] & Denmark & $\begin{array}{l}\text { Within the past } 5 \text { years } \\
\text { Changed profession or were no longer working: } 51 \% \\
\text { Changed profession: } 32.6 \% \\
\text { Outside the labour market: } 18.8 \% \\
\text { (NB: this is not necessarily due to hand eczema) } \\
\text { Participants who reported being 'clear' (with regard to hand eczema healing) } \\
\text { Changed profession or left the labour market: OR } 1.62 \text { (95\% CI 1.06-2.47) } \\
\text { Stayed in the same profession: OR } 2.85 \text { (95\% CI } 1.83-4.24 \text { ) [difference is significant] } \\
\text { More participants who changed profession or left their profession reported improvement in } \\
\text { their hand eczema compared with those who stayed in the same profession: OR } 1.91 \text { (95\% } \\
\text { CI } 1.44-2.54 \text { ) and } 1.51 \text { (95\% CI } 1.09-2.10 \text { ), respectively } \\
\text { Change of profession and being outside the labour market did not significantly influence the } \\
\text { number of severe cases at 4- to 5-year follow-up: OR } 0.75 \text { (95\% CI } 0.37-1.55 \text { ) and } 1.61 \\
\text { (95\% CI } 0.83-3.12 \text { ), respectively }\end{array}$ \\
\hline
\end{tabular}


Table 8 (continued)

References Country

Cvetkovski et al. [27] Denmark

Work impairment and missed work time

Cvetkovsi et al [27]

Cvetkovski et al. [46] Denmark

Hald et al. [22] Denmark

Lerbaek et al. [29] Denmark

Hald et al. [40] Denmark

Mollerup et al. [41] Denmark

Petersen et al. [23] Denmark

Steengaard et al. [31] Denmark

Sick leave due to occupational hand eczema in the past 12 months: 57\%

Job loss in the past 12 months: $22.9 \%$

More than 5 weeks per year of sick leave (prolonged sick leave): $19.9 \%$

Women had more prolonged sick leave than men in all age groups except the oldest group $(50+$ years $)$

Prolonged sick leave

Severe occupational hand eczema: $30 \%$

Either moderate or minimal occupational hand eczema: $17.6 \%$

Multivariate analysis predicting sick leave after 1-year follow-up for workers with occupational hand eczema

Significant predictors: aged 40-49 years compared with aged 18-24 years (RR 5.28, 95\% CI 1.4-20.7); severe symptoms compared with no/minimal symptoms (RR 5.29, 95\% CI 1.6-17.7); previous long-term sick leave compared with no previous long-term sick leave (RR 5.20, 95\% CI 2.0-13.6); low quality of life compared with high quality of life (RR $4.62,95 \%$ CI $1.6-13.7)$

Non-significant predictors ( $p$-values NR): sex, socioeconomic status, subdiagnosis, AD, duration of eczema, occupation, depression

CHE (i.e. patients with symptoms about half the time or more, or continuous symptoms the preceding year)

Sick leave within the past 12 months: $1 \%$

Mean duration of sick leave: 6 days

Changed jobs: $8.5 \%$

Sick leave

$<1$ week: $2.2 \%$

1-2 weeks: $4.3 \%$

3-5 weeks: $2.7 \%$

$>6$ weeks: $3.2 \%$

Total patients reporting sick leave: $12.4 \%$

Multivariate predictors of sick leave ever

Marginally significant predictors: AD yes vs. no: OR 2.9 (95\% CI 1.0-8.1), $p=0.05$ ); socioeconomic status $(0.05)$

Non-significant predictors: sex $(p=0.28)$; zygosity of twins $(p=0.84)$; age of onset $(0.54)$; positive patch test $(p=0.52)$

Patients reporting sick leave at baseline: $9.4 \%$

6-month follow-up (after seeing a dermatologist): $4.1 \%$

Sick leave within the last 12 months

Women: $24.5 \%$

Men: $10.7 \%$

Sick leave: $8 \%$ - most common in women $(p=0.007)$ and associated with severity of hand eczema at baseline $(p=0.029)$ and eczema on body locations other than the hands $(p=0.005)$

Job loss: $5 \%$

Sick leave in hairdressing-school participants

Intervention (selected teachers underwent a 2-day course in general skin physiology and prevention of hand eczema and allergy): $16.0 \%$

Control (traditional training): $8.7 \%, p=0.3$

Those who left their jobs who reported hand eczema as the reason for leaving: $12.5 \%$ 
Table 8 (continued)

\begin{tabular}{|c|c|c|}
\hline References & Country & Work impairment and missed work time \\
\hline van der Meer et al. [36] & The Netherlands & $\begin{array}{l}\text { Absenteeism } \\
\text { A survey of } 1178 \text { healthcare professionals revealed that } 403 \text { took sick leave. Of those who } \\
\text { took sick leave, } 1.0 \%(n=4) \text { was due to hand eczema, for an overall prevalence of } 0.3 \% \\
(n=2)[0.1-0.9 \%] \\
\text { 3-month prevalence of hand eczema: } 1.7 \%(n=2)[0.4-6.5 \%] \\
\text { Presenteeism: healthcare professionals for the past } 3 \text { months }(n=116)(\mathrm{CI}) \\
\text { Went to work at least } 1 \text { day while having hand eczema: } 84 \%(76-89 \%) \\
\text { Went to work }>30 \text { days while having hand eczema: } 22 \%(13-34 \%) \\
\text { Went to work on }>60 \text { days while having hand eczema: } 1.7 \%(0.4-6.6 \%) \\
\text { Presenteeism: amount of work performed on work days with HE (scale of } 0-10 \text { where } 0 \text { is } \\
\text { 'could not work' and } 10 \text { is 'same as usual') }(n=98) \\
\text { Mean: } 9.4 \text { (SE } 0.1) \\
\text { Median: } 10 \\
\text { Score } \leq 5: 3.4 \% \text { (CI } 1.4-8.0 \%) \\
\text { Score } \leq 9: 25 \% \text { (CI } 18-32 \%) \\
\text { Presenteeism: quality of work performed on work days with hand eczema (scale of } 0 \text { to } 10 \\
\text { where } 0 \text { is 'worst quality' and } 10 \text { is 'same quality as usual') }(n=98) \\
\text { Mean: } 9.5 \text { (SE } 0.1) \\
\text { Median: } 10 \\
\text { Score } \leq 5: 2.1 \% \text { (CI } 0.7-6.2 \%) \\
\text { Score } \leq 9: 26 \% \text { (CI } 17-37 \%)\end{array}$ \\
\hline
\end{tabular}

$A D$ atopic dermatitis, $C H E$ chronic hand eczema, $C I$ confidence interval, $N R$ not reported, $O R$ odds ratio, $R R$ risk ratio, $S D$ standard deviation, $S E$ standard error

with those in wet occupations $(20.1 \%)$ and other occupations $(16.5 \%)$.

Two German studies reported an annual mean of 7.2 days $(n=223)$ [14] and 35 days $(n=199)$ [17] of sick leave. The average duration of sick leave per episode due to CHE was 6 days in Denmark $(n=427)$ [22]. A Finnish study $(n=1238)$ reported that $6 \%$ of patients reported sick leave lasting at least 7 days in the past 12 months [24].

A study conducted in Germany and Switzerland ( $n=1466$ ) found that for food handlers, CHE was strongly associated with their ability to work and with taking sick leave [20]. A Danish study $(n=579)$ reported a higher proportion of prolonged sick leave among patients working in food-related occupations $(27.2 \%)$ compared with those in 'wet' occupations [where workers immerse their hands in liquids] (20.1\%) and other occupations (16.5\%) [27].

Presenteeism (working while sick) was reported in one study of Dutch healthcare professionals [36] $(n=1232)$. Of those with $\mathrm{CHE}$ for the past 3 months $(n=116), 84 \%$ went to work at least 1 day while having $\mathrm{CHE}, 22 \%$ went to work on more than 30 days while having $\mathrm{CHE}$, and $1.7 \%$ went to work on more than 60 days while having CHE. The 'amount of work performed' on workdays while having CHE $(n=98)$ was reported as a mean score of 9.4 (where 0 was 'could not work' and 10 was 'same as usual'). The 'quality of work performed' on workdays with HE $(n=98)$ was reported as 9.5 (where 0 was 'worst quality' and 10 was 'same quality as usual'). The study authors suggested that attending healthcare work despite their CHE may have unfavourable consequences for the patients of these healthcare professionals, such as not following hygiene protocols due to $\mathrm{CHE}$.

\subsubsection{Job Change}

Eleven studies reported job loss/job change due to $\mathrm{CHE}$ [19, 21, 23-25, 27-32], ranging from 3 to $25 \%$ (Table 8). Two German studies reported that $22 \%$ and $24.5 \%$ of patients with $\mathrm{CHE}$ were unable to work. One Finnish study $(n=1238)$ reported that $2 \%$ of patients received a sickness pension [24], while a Danish study $(n=50)$ reported that $13 \%$ of people with $\mathrm{CHE}$ who left their jobs reported hand, wrist and forearm eczema as the reason for leaving [31].

One study (three publications) conducted in Denmark reported that of 1496 participants, 32.6\% of patients with CHE changed profession and $18.8 \%$ were no longer working, however these changes were not necessarily due to $\mathrm{CHE}$ [33-35]. More participants who changed profession or left their profession reported improvement in their HE compared with those who stayed in the same profession.

\section{Discussion}

This review reports the available published current information on the direct and indirect costs of $\mathrm{CHE}$, including 30 studies conducted in Europe, Australia, New Zealand, and the Americas. The annual societal costs per patient of CHE ranged between $\$ 2549$ (€1813) [30\% direct costs, 70\% indirect costs] and \$10,883 (€7738) [49\% direct costs, 51\% 
indirect costs] in Europe and is reported as \$5425 (€3857) per patient in the US. The highest estimate was in patients with occupation-related CHE. Overall, the mean number of consultations per month was as high as 3.1, in part due to patch test visits. However, in most studies it was close to once every 2 months. Most studies reported that more than $20 \%$ of participants took sick leave due to CHE; the mean number of days of sick leave ranged from 7.2 to 35 days per year. The effect of CHE on presenteeism is unclear, although widespread. These findings demonstrate that CHE has a significant cost burden, both directly and indirectly through its effect on work productivity.

In comparison with other dermatological conditions, the direct annual costs of psoriasis in the US has been estimated at between $\$ 8000$ and $\$ 9777$ ( $€ 5688$ and $€ 6952$ ) per patient, translating to an annual economic burden to the US of between $\$ 59.2$ and $\$ 72.5$ billion ( $€ 42.1$ and $€ 51.5$ billion) [42]. The annual indirect costs per patient have been estimated at between $\$ 3695$ and $\$ 3915$ ( $€ 2627$ and $€ 2783$ ) translating to an annual economic burden of between $\$ 27.4$ and $\$ 40.7$ billion ( $€ 19.5$ and $€ 28.9$ billion) [42]. In a German cross-sectional study, the average annual total cost of psoriasis was reported to be $\$ 9820$ ( $€ 6982$ ) per person [43]. An estimate of the annual cost of AD to the US has been reported as $\$ 5.92$ billion ( $€ 4.21$ billion) [costs per patient were not reported] [44]. However, because the current costs are typically estimated using an 'average' CHE patient rather than by disease severity, and because patients with CHE may be difficult to identify given the lack of standardisation in the definition of CHE, the true cost for CHE may be higher. Other costs that may not have been factored into the estimates include disability costs associated with CHE.

The available primary studies have shortcomings that may have impacted on the results of this analysis. The previous lack of a standardised definition of CHE and CHE severity hamper a synthesis of the monetary costs attributable to sick leave and job loss associated with CHE. There is no available information on the extent and impact of CHE as a cause of permanent disability or potential additional costs in patients with more severe or uncontrolled disease. Most study patients were often from managed care populations who, for example, had health insurance or represented specific occupational groups. Identifying CHE patients in research and administrative databases is challenging as there is currently no International Classification of Diseases, Ninth/Tenth Revision (ICD-9/10) code for CHE, although the ICD, Eleventh Revision (ICD-11; effective January 2022) may include disease areas not covered by ICD-10, therefore future research may be able to identify patients with CHE. With few treatments indicated for CHE, and that vary across territories, this makes it challenging to identify data linked to specific treatments. Classifying disease severity based on clinical characteristics is also difficult due to the lack of structured data from many existing databases.

The synthesis of data for this review also had limitations. The cost-of-illness studies identified were from a limited number of studies and countries in Europe (Germany, Italy, and The Netherlands) and in the US, which could limit the generalisability of the data. The sample of studies that were included are heterogenous, and the studies' sampling methods and population characteristics may also hamper generalisability. In particular, in many of the resource use studies, the study patients were often from specific populations. Although the economic data were uplifted to current costs, most costs data have come from studies older than 10 years, meaning the data may not reflect current practice.

\subsection{Implications for Future Research}

Understanding costs is important to inform healthcare resource allocation decisions and to gain insight into the economic burden for patients and payers. More current data would be helpful for economic modelling and for estimating cost of illness. Evaluations should involve longer treatment durations and follow-up periods. Studies on costs and healthcare resource utilization should obtain data for different groups of CHE patients representing a spectrum of regions, disease severity, social health determinants (and other environmental factors) and occupations. Studies of indirect costs should take account of presenteeism, which has not been widely reported to date. Future research needs to continually evaluate the costs associated with existing therapies (such as biologics [45]) and emerging therapies in patients with CHE. For example, while alitretinoin has been approved for severe CHE in regions including the $\mathrm{EU}$, its use in the treatment algorithm from various regions and the associated costs need to be better characterized [6]. Given the recent and ongoing development of newer therapies, the financial burden of CHE may be higher than currently estimated.

\section{Conclusions}

This review has confirmed that CHE has a significant cost burden. Given the increased risk of CHE in some occupations, it is clear that CHE has a significant economic impact on both patient and society due to job loss and presenteeism, which are insufficiently assessed in the literature. Finally, researchers and clinicians should continually strive to determine the lifetime burden of CHE and develop efficacious and safe therapies to reduce the physical, psychosocial and economic burden to CHE.

Supplementary Information The online version contains supplementary material available at https://doi.org/10.1007/s40257-021-00669-6. 
Acknowledgements The authors thank Sarah King, Anita Fitzgerald, Eydna Didriksen Apol, Bibi Petersen and Claire Bark for valuable assistance in drafting the manuscript, as well as Karen Bartlett, who contributed to the formatting of this manuscript.

\section{Declarations}

Funding The authors disclose receipt of financial support from Leo Pharma A/S for the research, authorship, and publication of this article.

Conflicts of interest/competing interests Jacob Thyssen has been an advisor/investigator or speaker for Abbvie, Pfizer, LEO Pharma, Regeneron, Sanofi Genzyme and Eli Lilly \& Co. Julie Hahn-Pedersen is a former employee of LEO Pharma, who sponsored this review. Chris Bartlett (and formerly, Julie Glanville) is employed by York Health Economics Consortium, which received funding from LEO Pharma to conduct this review. April Armstrong has served as a research investigator or consultant to AbbVie, ASLAN, BI, BMS, EPI, Incyte, Leo, UCB, Janssen, Lilly, Novartis, Ortho Dermatologics, Sun, Dermavant, Dermira, Sanofi, Regeneron, Pfizer, and Modmed.

Ethics approval Not applicable.

Consent to participate Not applicable.

Consent for publication Not applicable.

Availability of data and material Not applicable.

Code availability Not applicable.

Author contributions CB and JG developed the protocol, including formulation of the search strategy, managed the review production and contributed to data interpretation, and were also involved in drafting the manuscript. $\mathrm{CB}, \mathrm{JG}, \mathrm{JH}-\mathrm{P}, \mathrm{AA}$ and $\mathrm{JT}$ approved the final version for submission and agree to be accountable for all aspects of the work.

Open Access This article is licensed under a Creative Commons Attribution-NonCommercial 4.0 International License, which permits any non-commercial use, sharing, adaptation, distribution and reproduction in any medium or format, as long as you give appropriate credit to the original author(s) and the source, provide a link to the Creative Commons licence, and indicate if changes were made. The images or other third party material in this article are included in the article's Creative Commons licence, unless indicated otherwise in a credit line to the material. If material is not included in the article's Creative Commons licence and your intended use is not permitted by statutory regulation or exceeds the permitted use, you will need to obtain permission directly from the copyright holder. To view a copy of this licence, visit http://creativecommons.org/licenses/by-nc/4.0/.

\section{References}

1. Politiek K, Oosterhaven JAF, Vermeulen KM, Schuttelaar M-LA. Systematic review of cost-of-illness studies in hand eczema. Contact Derm. 2016;75(2):67-76.

2. Capucci S, Hahn-Pedersen J, Vilsboll A, Kragh N. Impact of atopic dermatitis and chronic hand eczema on quality of life compared with other chronic diseases. Dermatitis. 2020;31(3):178-84.

3. Agner T, Elsner P. Hand eczema: epidemiology, prognosis and prevention. J Eur Acad Dermatol Venereol. 2020;34(Suppl 1):4-12.
4. Meding B, Wrangsjo K, Jarvholm B. Fifteen-year follow-up of hand eczema: persistence and consequences. Br J Dermatol. 2005;152(5):975-80.

5. Mollerup A, Veien NK, Johansen JD. Chronic hand eczema-selfmanagement and prognosis: a study protocol for a randomised clinical trial. BMC Dermatol. 2012;12:6.

6. Diepgen TL, Andersen KE, Chosidow O, Coenraads PJ, Elsner P, English J, et al. Guidelines for diagnosis, prevention and treatment of hand eczema. J Dtsch Dermatol Ges. 2015;13(1):e1-22.

7. Centre for Reviews and Dissemination. Systematic reviews: CRD's guidance for undertaking reviews in health care. York. 2009. https://www.york.ac.uk/media/crd/Systematic_Reviews.pdf. Accessed Sept 2019.

8. Higgins JPT, Savovic J, Page MJ, Elbers RG, Sterne JAC. Chapter 8: assessing risk of bias in a randomized trial. In: Higgins JPT, Thomas J, Chandler J, Cumpston M, Li T, Page MJ (eds) Cochrane handbook for systematic reviews of interventions (version 6) [updated July 2019]. Cochrane. 2019. https://training.cochr ane.org/handbook/current/chapter-08. Accessed Sept 2019.

9. Fxtop. Inflation calculator. Fxtop; 2019. Last updated daily. https://www.google.com/url?q=https://fxtop.com/en/inflationcalculator.php\&sa $=$ D\&ust $=1571309861183000 \& u s g=A F Q j C$ NGnnNYUiAuVju4cELgdC8rrn4DWQQ. Accessed Oct 2018 and Sep 2019.

10. OECD Data. Purchasing power parities (PPP). Paris: OECD.org. https://www.google.com/url?q=https://data.oecd.org/conversion/ purchasing-power-parities-ppp.htm\&sa=D\&ust $=1571309861$ 183000\&usg =AFQjCNHGniEAC6BydfdtDfJTT9uwO2EqJw. Accessed Sep 2019.

11. Blank PR, Blank AA, Szucs TD. Cost-effectiveness of oral alitretinoin in patients with severe chronic hand eczema-a long-term analysis from a Swiss perspective. BMC Dermatol. 2010;10(4):1-9.

12. National Institute for Health and Care Excellence. Single technology appraisal (STA) specification for manufacturer/sponsor submission of evidence. London: National Institute for Health and Care Excellence. 2008. https://www.nice.org.uk/guidance/ta177. Accessed Sept 2019.

13. van Gils RF, Bosmans JE, Boot CRL, Rustemeyer T, van Mechelen W, van der Valk PGM, et al. Economic evaluation of an integrated care programme for patients with hand dermatitis. Contact Derm. 2013;69(3):144-52.

14. Augustin M, Kuessner D, Purwins S, Hieke K, Posthumus J, Diepgen TL. Cost-of-illness of patients with chronic hand eczema in routine care: results from a multicentre study in Germany. Br J Dermatol. 2011;165(4):845-51.

15. Cortesi PA, Scalone L, Belisari A, Bonamonte D, Cannavo SP, Cristaudo A, et al. Cost and quality of life in patients with severe chronic hand eczema refractory to standard therapy with topical potent corticosteroids. Contact Derm. 2014;70(3):158-68.

16. Fowler JF, Ghosh A, Sung J, Emani S, Chang J, Den E, et al. Impact of chronic hand dermatitis on quality of life, work productivity, activity impairment, and medical costs. J Am Acad Dermatol. 2006;54(3):448-57.

17. Diepgen TL, Purwins S, Posthumus J, Kuessner D, John SM, Augustin M. Cost-of-illness analysis of patients with chronic hand eczema in routine care in Germany: focus on the impact of occupational disease. Acta Derm Venereol. 2013;93(5):538-43.

18. Agner T, Andersen KE, Brandao FM, Bruynzeel DP, Bruze M, Frosch $\mathrm{P}$, et al. Contact sensitisation in hand eczema patientsrelation to subdiagnosis, severity and quality of life: a multi-centre study. Contact Derm. 2009;61(5):291-6.

19. Herschel S, Schmitt J, Bauer A. Satisfaction with medical treatment in patients with hand dermatitis - a cross-sectional study. J Dtsch Dermatol Ges. 2013;11(10):1007-13. 
20. Cazzaniga S, Apfelbacher C, Diepgen T, Ofenloch RF, Weisshaar E, Molin S, et al. Patterns of chronic hand eczema: a semantic map analysis of the CARPE registry data. Br J Dermatol. 2018;178(1):229-37.

21. Dibenedetti D, Baranowski E, Zelt S, Reynolds M, Sherrill B. Assessing United States patient and dermatologist experiences with severe chronic hand eczema. J Clin Aesthet Dermatol. 2015;8(11):19-27.

22. Hald M, Berg ND, Elberling J, Johansen JD. Medical consultations in relation to severity of hand eczema in the general population. Br J Dermatol. 2008;158(4):773-7.

23. Petersen AH, Johansen JD, Hald M. Hand eczema-prognosis and consequences: a 7-year follow-up study. Br J Dermatol. 2014;171(6):1428-33.

24. Thyssen JP, Johansen JD, Linneberg A, Menne T. The epidemiology of hand eczema in the general population-prevalence and main findings. Contact Derm. 2010;62(2):75-87.

25. Apfelbacher C, Weis M, Molin S, Weisshaar E, Bauer A, Mahler $\mathrm{V}$, et al. Medical care of patients with chronic hand eczema: carpe registry. Contact Derm. 2012;66(Suppl 2):17.

26. Diepgen TL, Kuessner D. Sickness absences due to chronic hand eczema (CHE) in patients treated with oral alitretinoin under daily practice conditions: results of the toccata observational study comprising 522 workers. Value Health. 2012;15(4):A253.

27. Cvetkovski RS, Rothman KJ, Olsen J, Mathiesen B, Iversen L, Johansen JD, et al. Relation between diagnoses on severity, sick leave and loss of job among patients with occupational hand eczema. Br J Dermatol. 2005;152(1):93-8.

28. Josefson A, Farm G, Stymne B, Meding B. Nickel allergy and hand eczema - a 20-year follow up. Contact Derm. 2006;55(5):286-90.

29. Lerbaek A, Kyvik KO, Ravn H, Menne T, Agner T. Clinical characteristics and consequences of hand eczema-an 8-year follow-up study of a population-based twin cohort. Contact Derm. 2008;58(4):210-6.

30. Malkonen T, Alanko K, Jolanki R, Luukkonen R, Aalto-Korte K, Lauerma A, et al. Long-term follow-up study of occupational hand eczema. Br J Dermatol. 2010;163(5):999-1006.

31. Steengaard SS, Bregnhoj A, Johansen JD. Hand eczema among hairdressing apprentices in Denmark following a nationwide prospective intervention programme: 6-year follow-up. Contact Derm. 2016;75(1):32-40.

32. Apfelbacher CJ, Ofenloch RF, Weisshaar E, Molin S, Bauer A, Mahler V, et al. Chronic hand eczema in Germany: 5-year follow-up data from the CARPE registry. Contact Derm. 2019;80(1):45-53.

33. Agner T. Job change in employees with occupational hand eczema. Contact Derm. 2018;79(Suppl 1):51.
34. Caroe TK, Ebbehoj NE, Bonde JPE, Vejlstrup SG, Agner T. Job change facilitates healing in a cohort of patients with occupational hand eczema. Br J Dermatol. 2017;179(1):80-7.

35. Caroe TK, Ebbehoj NE, Bonde JPE, Vejlstrup SG, Agner T. Occupational hand eczema and job change. Br J Dermatol. 2018;179(1): e68.

36. van der Meer EWC, Boot CRL, van der Gulden JWJ, Jungbauer FHW, Coenraads PJ, Anema JR. Hand eczema among healthcare professionals in the Netherlands: prevalence, absenteeism, and presenteeism. Contact Derm. 2013;69(3):164-71.

37. Apfelbacher C, Weiss M, Molin S, Bauer A, Mahler V, Schmitt $\mathrm{J}$, et al. Antihistamine use in patients with chronic hand eczema: an analysis based on data from the German carpe registry. Exp Dermatol. 2015;24(3):E16.

38. Apfelbacher C, Weis M, Molin S, Bauer A, Mahler V, Schmitt $\mathrm{J}$, et al. Which factors are associated with the use of systemic antihistamines in patients with chronic hand eczema? Results from the CARPE registry. J Eur Acad Dermatol Venereol. 2016;30(1):50-6.

39. Diepgen TL, Andersen KE, Brandao FM, Bruze M, Bruynzeel DP, Frosch P, et al. Hand eczema classification: a cross-sectional, multicentre study of the aetiology and morphology of hand eczema. Br J Dermatol. 2009;160(2):353-8.

40. Hald M, Agner T, Blands J, Johansen JD, Danish Contact Dermatitis G. Delay in medical attention to hand eczema: a follow-up study. Br J Dermatol. 2009;161(6):1294-300.

41. Mollerup A, Veien NK, Johansen JD. An analysis of gender differences in patients with hand eczema-everyday exposures, severity, and consequences. Contact Derm. 2014;71(1):21-30.

42. Brezinski EA, Dhillon JS, Armstrong AW. Economic burden of psoriasis in the United States: a systematic review. JAMA Dermatol. 2015;151(6):651-8.

43. Jungen D, Augustin M, Langenbruch A, Zander N, Reich K, Strömer K, et al. Cost-of-illness of psoriasis-results of a German cross-sectional study. J Eur Acad Dermatol Venereol. 2018;32(1):174-80.

44. Drucker AM, Wang AR, Li W-Q, Sevetson E, Block JK, Qureshi AA. The burden of atopic dermatitis: summary of a report for the national eczema association. J Invest Dermatol. 2017;137(1):26-30.

45. Armstrong AW, Huang A, Wang L, Miao R, Patel MY, Gadkari A, et al. Real-world utilization patterns of systemic immunosuppressants among US adult patients with atopic dermatitis. PLoS ONE. 2019;14(1): e0210517.

46. Cvetkovski RS, Zachariae R, Jensen H, Olsen J, Johansen JD, Agner T. Prognosis of occupational hand eczema: a follow-up study. Arch Dermatol. 2006;142(3):305-11. 